\title{
DEPARTMENT OF RHINOLOGY
}

\author{
EDITED BY
}

\author{
REGINALD R. WALKER, M. D. \\ WASHINGTON, D. C.
}

\section{THE RELATIONSHIP BETWEEN RHINOLOGY AND ORTHODONTIA.*}

\author{
By Dean W. Myers, M. D., AnN Arbor, Michigan.
}

\begin{abstract}
TN THE brief consideration of this, to me, exceedingly interesting subject, 1 it is not my desire or intention to enter at all into a technical or hypothetical discussion, rather do I hope to suggest some practica idea, and my purpose shall have been accomplished if the effort results, some time, in profit to a few at least of our little patients.

Like the "poor that are ever with us" so are we always surrounded by a horde of unfortunate victims of abnormal respiration. Nature is a wonderful builder, but in this particular she has seriously missed the "plane." Consequently to our lot comes the responsible work of building over, and to this end our colleague in human effort, the orthodontist, has come forward with invaluable assistance; it is to suggest his usefulness to ourselves and our patients that I attempt a presentation of this subject.
\end{abstract}

\section{Mouth-Breathing.}

It has remained for this broth $\mathrm{r}$ of ours, the orthodontist, to call our attention to the fact that mouth-breathing may result from other causes than nasal or pharyngeal obstruction. He has been able to tell us why so many of our "brilliant" operations in the nose and throat have failed utterly to establish normal respiration, and he has also been able to show us that mouth-breathing with open nasopharynx is not entirely due to that much abused term "habit." I venture to say that there is not one within the radius of my voice today who has not had one or more occasions in which he has said to the waiting parents: "Your child has no adenoids, its tonsils are normal and its nasal passages are free, therefore it must breathe through its mouth purely from habit." I will also venture that when alone, thereafter, he has asked himself in good faith: "What is habit mouthbreathing? Why should it be, when the nose was clearly intended for the purpose?" I confess the orthodontist has answered this oft repeated question for me; to him I am indebted and to him I feel grateful.

For convenience in considering this subject, let us divide mouthbreathers into two classes:

Class I.-Those who breathe through the mouth because of some nasal or nasopharyngeal obstruction, as nasal hypertrophies, adenoids or enlarged tonsils. 
Class II.-Those who breathe through the mouth, but are found to have normal nasopharyngeal passages; in other words, those who breathe through the mouth because of an abnormal development of the dental arches resulting in malocclusion of the teeth.

Further, Class I may be subdivided into two divisions:

Division 1.-Nasal obstruction with normal dental arches and normal occlusion of the teeth.

Division 2.-Nasal obstruction resulting in abnormal development of the dental arches and malocclusion of the teeth.

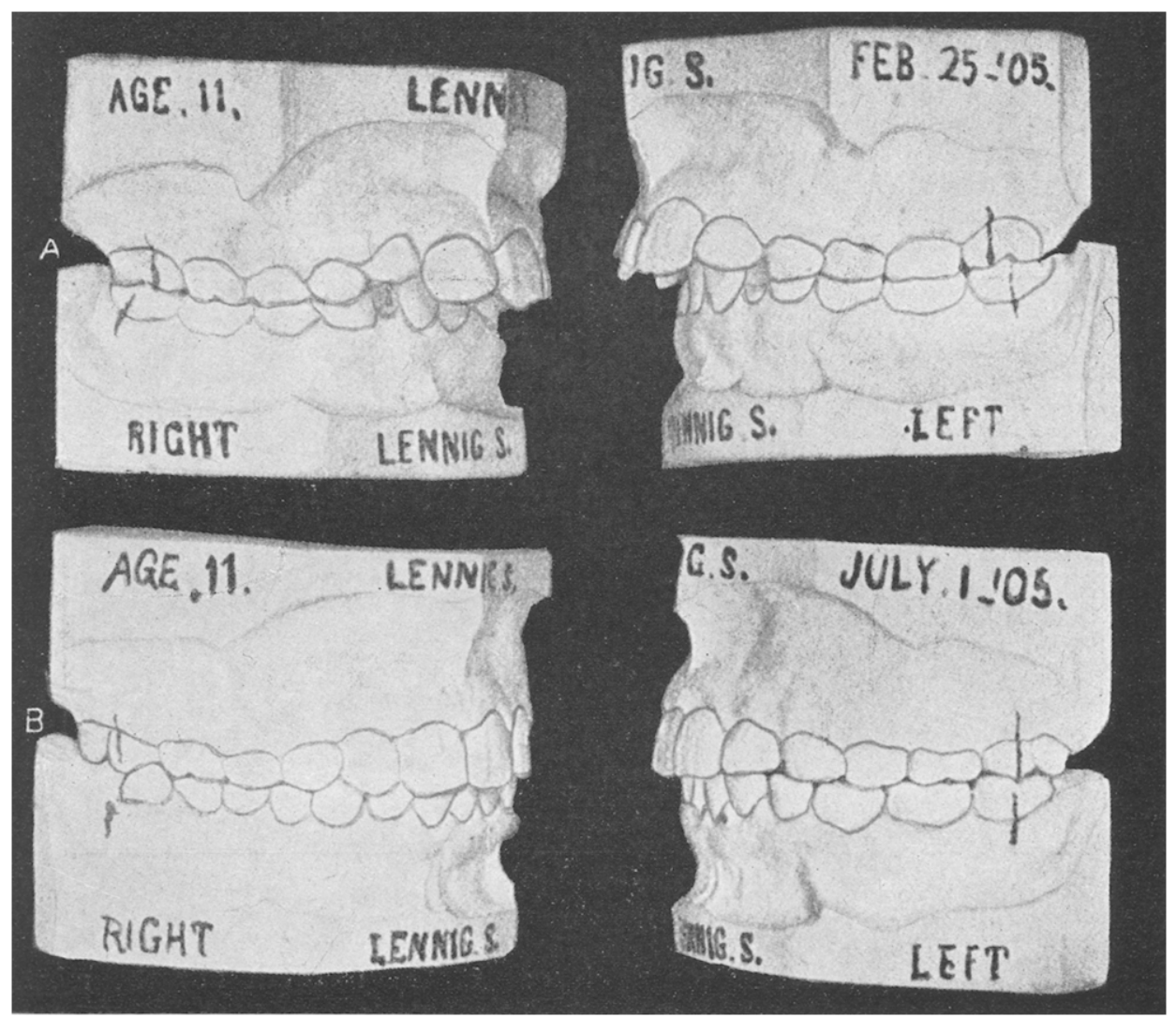

Fig. 1.-Models illustrating” protruding and receding lower incisors]beforejand after correction (Ketcham).

Class II may also be subdivided into two divisions:

Division 1.-Irregular development of the dental arches due to nasopharyngeal obstructions, these obstructions having remained long enough, before removal or disappearance, to act as etiological factors in the abnormal shaping of the arches; and,

Division 2.- Irregular dental arches and malocclusion of the teeth in which malnutrition, infantile congestive obstructions or faulty ossification processes have been etiological factors.

Etiological Factors.-As to the etiology of adenoids and other lymphoid hypertrophies, I purpose simply to suggest two classes which will, I think, be self-explanatory, i.e., (1) Those due to hereditary or constitutional 
influences, and (2) Those resulting from external influences, as repeated attacks of "cold in the head," influenza, acute febrile diseases, etc., ad lib.

To take up briefly Class I-cases of mouth-breathing due to nasal or nasopharyngeal obstruction and its two divisions, i.e., those with (1) normal, and (2) abnormal dental arches - we find the subjects who possess normal dental arches, but an occluded nasopharynx will prove to be the ones in which the lymphoid hypertrophies have developed after the twelfth to fifteenth year, and are consequently due to external causes, as mentioned above. This class of cases is rare, being supplanted by the much more common division in which nasal or nasopharyngeal obstruction has appeared much earlier and is found to be accompanied by an abnormally developed denta! arch. This type of dental deformity resulting in malocclusion of the teeth is easily accounted for, and the explanation which I shall make use of is by no means new.

I agree with Bogue, of New York, that too frequently the importance of the muscular action of the tongue in the development of the superior

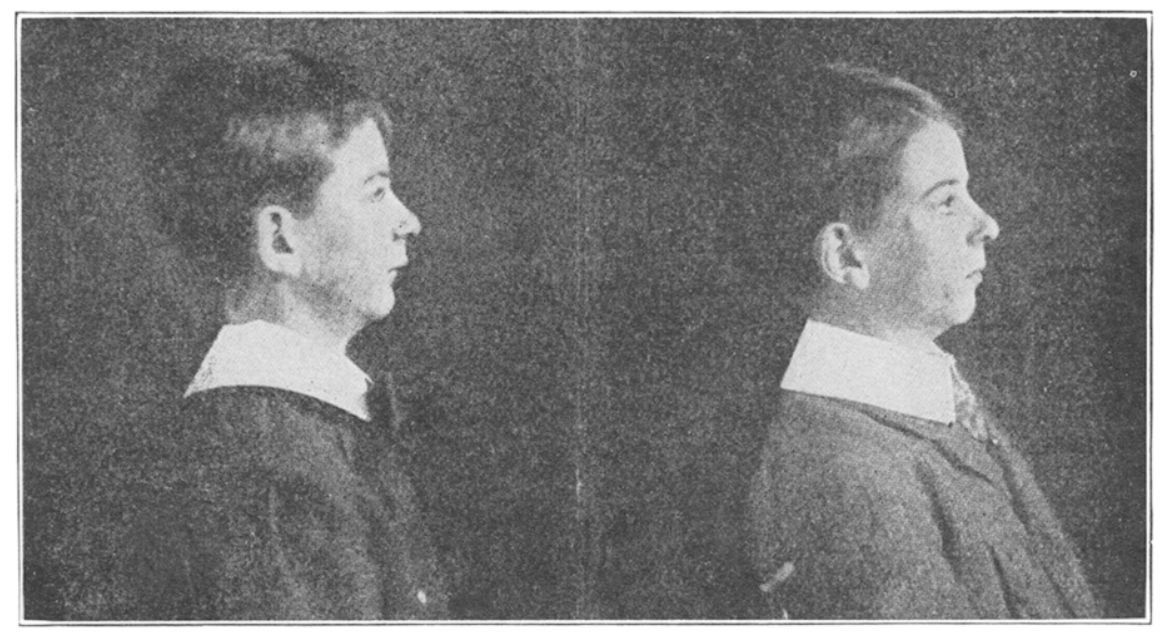

Fig. 2.-Profile of case from which model A and B of Fig. 1 were taken, showing the great improvement in facial outline as well as normal closure of the mouth (Ketcham).

maxilla is overlooked. The tongue is one of the most, if not the most, powerful muscle or group of muscles in the whole human body. Its great strength is encountered every day by rhinolaryngologists and orthodontists the country over. Its normal position when the mouth is closed and nasal respiration is taking place, is pressed against the roof of the mouth and laterally against the inner surfaces of the alveolar processes. It must not be forgotten that these processes are, in these subjects, pliable and subject to the greatest diversity of shape due to slight external influences. Therefore, The Great Creator intended that in the process of normal development this muscular influence should be constantly exterted from within to widen out and bring into opposition the upper arch with its fellow, the mandible. Open the mouth for purposes of respiration and this muscular pres ure is at once removed to the floor of that passage, and the maxillary arch, from lack of support from within and with pressure from without, becomes narrowed and elongated and the protruding upper incisors, so familiar to us all, 
is the result. This condition accompanies nasal obstruction usually without tonsilar enlargement. Early and continued hypert ophy of the faucial tonsils, resulting in the extension forward of the lower jaw to open the oropharynx, gives us the prominent chin and receding upper lip of the so-called wapper-jawed individual, except, perhaps, in such rare cases of protrud ng lower jaw as are clearly due to accidental dental causes.

Considering briefly the second class of cases, i.e., mouth-breathers who have normal nasopharyngeal passages, or in other words those who breathe through the mouth because of abnormal dental arches and resulting malocclusion of the teeth, it will be noted that the first division of this class of individuals are the incomplete results of rhinological efforts upon cases in

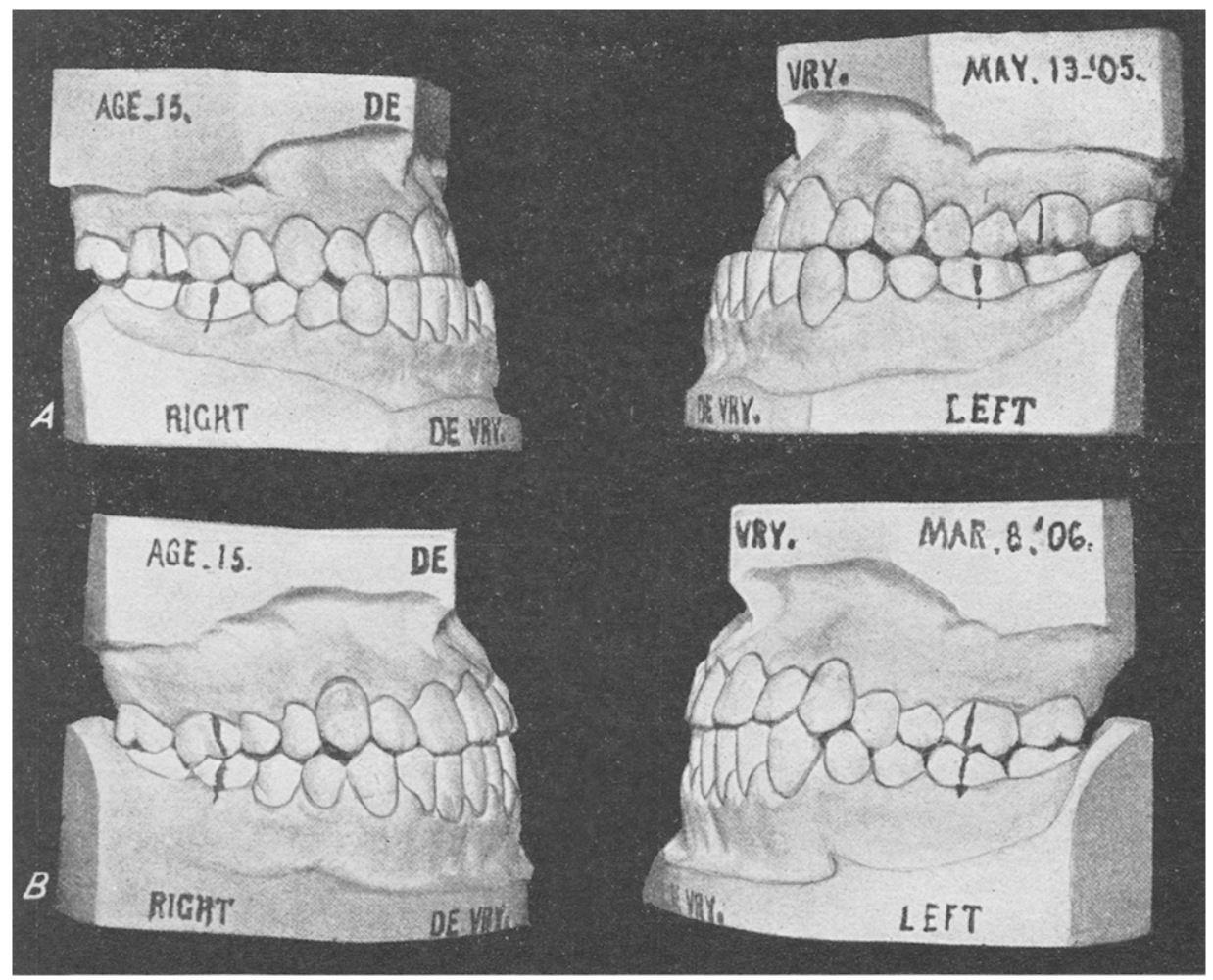

Fig. 3.-Illustrating the protruding lower $j$ aw of the so-called wapper-jawed individual. Seen also in profile and front views (before and after treatment) in Figs. 4 and 5 (Ketcham).

Division 2 of Class $\mathrm{I}$, in the above classification, adenoid, etc., having been removed, but dental deformities still remaining.

The second variety will be found to be those having irregular dental arches and consequent malocclusion, but no history of nasal obstruction will be obtainable, and I have ascribed to this variety as etiological factors, malnutrition, infantile congestive obstructions and faulty ossification processes.

This second class, with its two divisions as mentioned above, i.e., those in which mouth-breathing persists after normal nasal passages have been established and continues in spite of efforts innumerable to "break the habit," is the "exciting cause" for an attempt on my part to present this subject to you today. With the malocclusion developed, of whatever type, 
whether it be the protruding upper incisors with receding chin, or the protruding lower jaw with depressed upper lip, or that other common type in which the jaws are very much underdeveloped and the teeth crowded and overlapped, the result must be the same and nasal respiration will not take place, no matter how free the nasal passages may be. In the first case, the
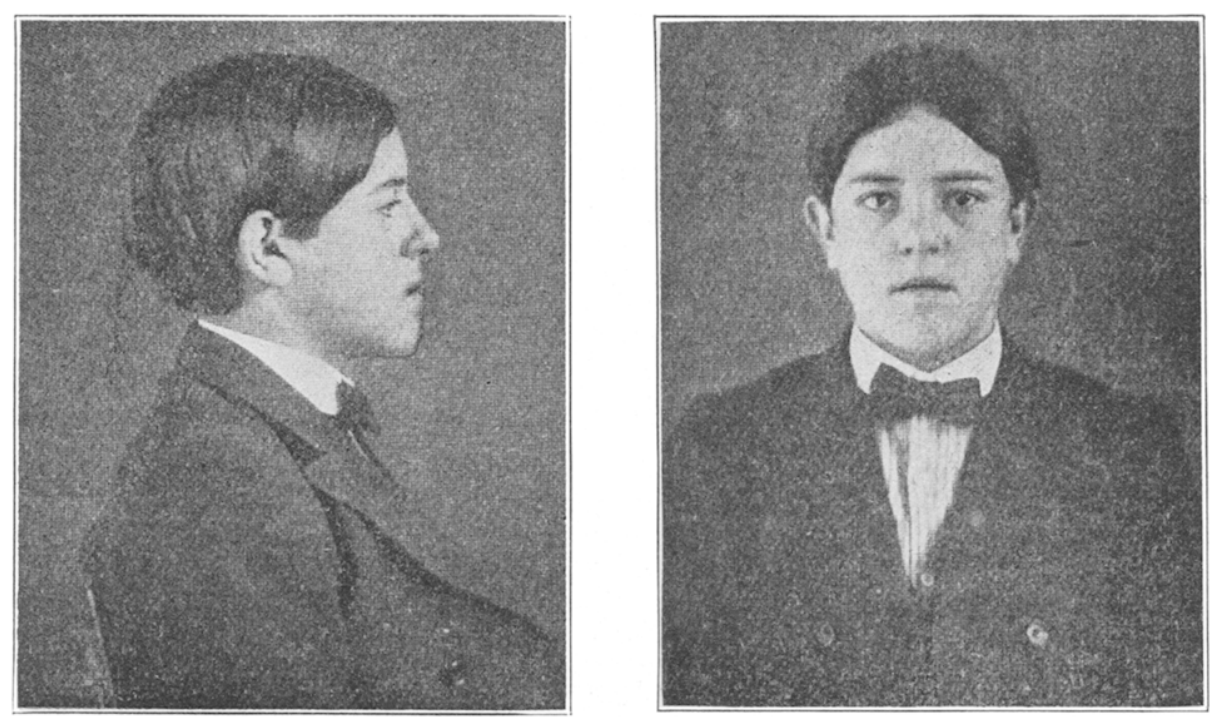

Fig. 4.
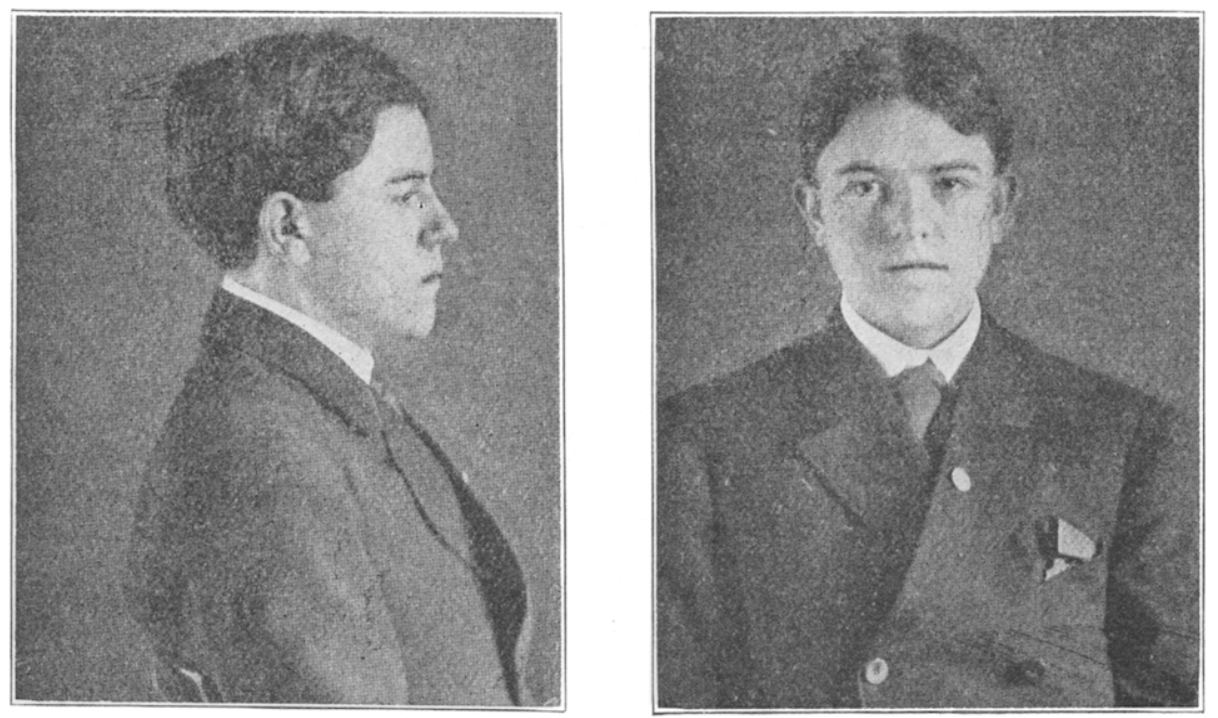

Fig. 5.

protruding upper incisors project beyond the lower lip, which, without the patient's volition, slips up behind and underneath these teeth creating an air passage by means of which the mouth is soon forced open and oral respiration follows. With the projecting lower jaw the same process, reversed, results. The upper lip recedes behind the prominent lower incisors, and 
air at once passes within and the jaw drops in spite of the patient. In the type in which the jaws are very much underdeveloped, there will be found a corresponding narrowing of the nasal passages rendering nasal breathing difficult. Therefore, to sum up, nasal respiration cannot be maintained when closure of the mouth is secured at the expense of an effort, this constant effort being necessary when malocclusion of the teeth is present.

Prognosis.-As rhinologists we have always been ready to predict splendid results from removal of adenoid tissue, hypertrophied tonsils or any existing nasal deformity. We have pictured in glowing terms the splendid results of our many ministrations and the brilliancy of our numerous surgical sallies upon these little unfortunates. But have we not, many times, within the confines of our own consciences admitted our utter defeat?

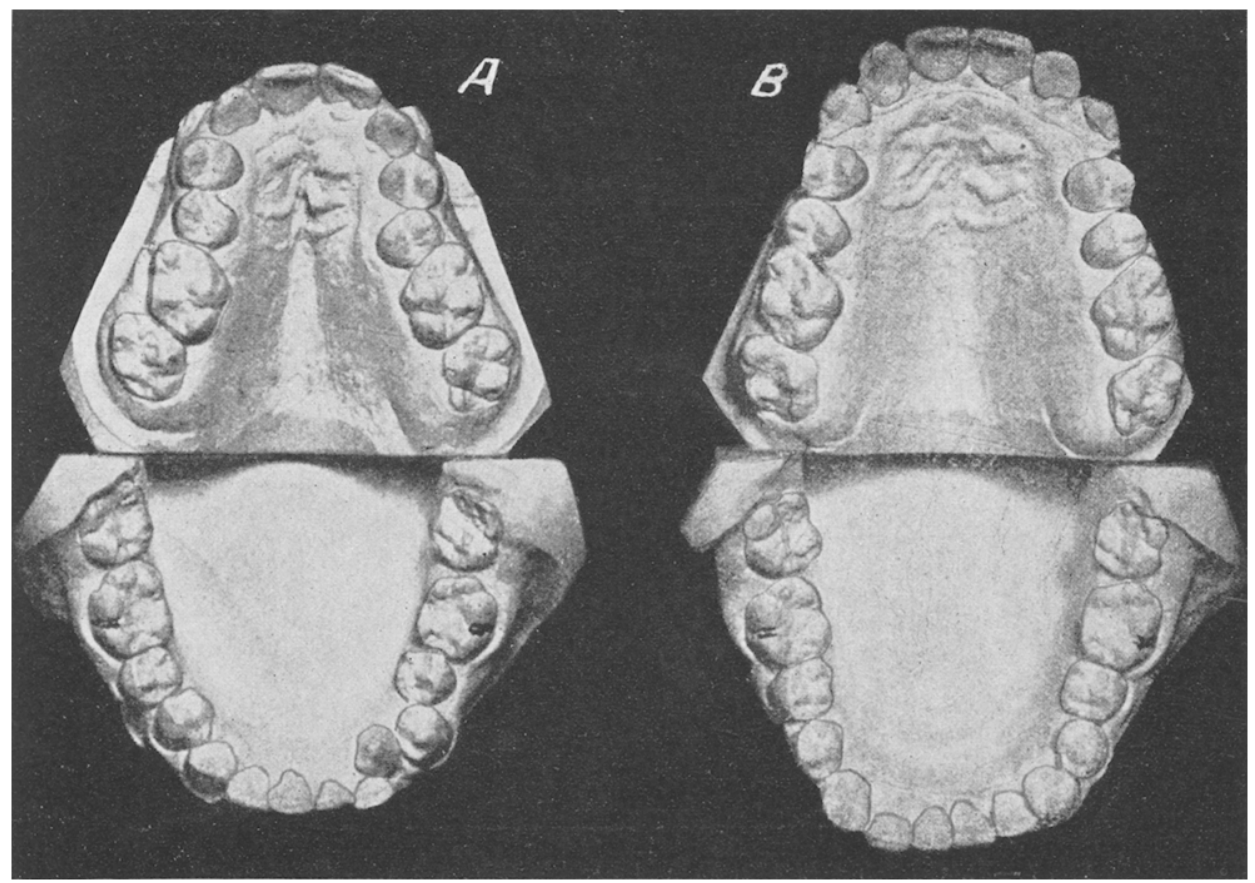

Fig. 6.-Showing an underdeveloped jaw with teeth crowded and overlapped. A corresponding narrowing of the nasal passages accompanies this condition (Ketcham).

Great as may have been the necessity for our part in the performances, and faithfully as we have carried it out, has it not been the lot of all of us, on many occasions, to find ourselves confronted by absolute failure to establish that for which we set out? And have not many, many of our patients gone on breathing through their mouths continuously after we have heroically removed "everything in sight."

From the orthodontist's standpoint the outlook is coming to be much less gloomy. Without the rhinologist to remove respiratory obstructions his work would be a failure, and so without the orthodontist to correct the dental deformities in our mouth-breathers we have been doomed to defeat and will continue to be so doomed until we recognize him and make him our most valuable assistant. 
It is now a well recognized fact that the bones of the face and jaws are susceptible to great alterations in shape if taken at the proper time of life. Dentists recognize the possiblity of influencing the growth and position of the second set of teeth by giving early attention to the primary set. Thus what might become an irregular maxilla containing misplaced teeth, failing to occlude with their fellow opponents of the lower jaw, may be developed into a normally formed process by proper regulation of the first set.

With these facts before us it will be much easier to make a favorable prognosis as to complete relief from obnoxious and health impairing mouthbreathing.

Treatment.- In the treatment of mouth-breathers, two objects should always be kept in mind:

1st. The establishment of a free, open, normal nasopharyngeal passage for the air.

$2 \mathrm{~d}$. The procuring of a normal occlusion of the teeth, or as nearly so as possible, that nasal respiration may be maintained.

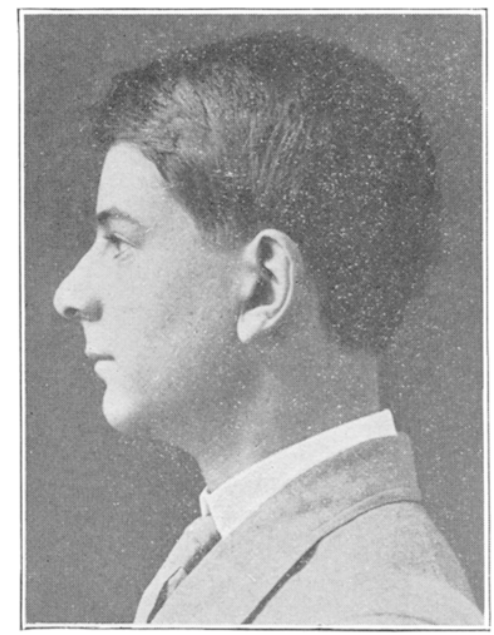

Fig. 7.-Photograph of case shown in Fig. 1, taken February, 1909 (Ketcham).

The methods for the first requisites are so well known to all that comment upon them is wholly unnecessary. For the second a few words may not be amiss.

Dr. Angle - a celebrated orthodontist, the first to discover the upper first permanent molar as a fixed point in the arch from which to make a diagnosis-speaking from the standpoint of his profession, says that "in the treatment of all cases of malocclusion our efforts should be toward the accomplishing of three main objects:

"First, correction of malocclusion.

"Second, establishment of harmony in the relation of the jaws.

"Third, improvement of the facial lines. In the accomplishment of these, our efforts should be toward the ideal, where normal occlusion, normal relation of the jaws and harmony of facial lines are combined. While the 
ideal is not always possible to attain, yet the best attainable results cannot be hoped for with a lesser standard."

To these I would add a

Fourth, i.e., the establishment of normal respiration.

Indeed, I would class this as the first and most important object to which all efforts of both rhinologists and orthodontists should be directed. In this day of progress, when we are hearing so much about the great white plague, and the noble battle being waged against its ravages, it seems to me that we cannot do better than to consider seriously the influence of abnormal respiration as an etiological factor in the development of pulmonary tubercular affections, for where better can the treatment of phthisis pulmonalis be commenced than before the diseas has actually begun? I believe that all our efforts toward the stamping out of this great scourge will be of no avail until we recognize the importance of, and meet the conditions existing before the disease has actually started.

To this end we must recognize the great importance of the normal functions of the nose. As is well known, its principal duty, so far as respiration is concerned, is to warm, moisten and filter the inspired air. We know that at 32 degrees F. air, to be saturated, requires 2.1 grains of water to the cubic foot. According to Aschenbrandt and Kayser, the inspired air receives from 20 degrees to 40 degrees of heat and becomes saturated, or nearly so, in its passage through the nose. This renders it suitable for the interchange of oxygen and carbonic acid gas in the lungs, a simple action of osmosis which takes place most perfectly when with warm fluid on one side of a membrane there is warm, moist air on the other. Bosworth concludes that the nose must supply in twenty-four hours about a pint of moisture for this purpose, which it obtains from the sinus tissues of the turbinates, together with the tears and the secretions of the muciparous glands.

The function of the nose in filtering the inspired air is practically perfect, Tyndall having demonstrated that expired air is free from germs. St. Clair Thompson and Hewlett, a few years ago, concluded that the nose does not offer as fertile a soil for micro-organisms as does the oropharynx, for according to their researches the occurrence of micro-organisms on the Schneiderian membrane is so infrequent that their presence must be regarded as quite exceptional. Paget confirmed these results, finding the nasal cavities in the normal state free from microbes except at the anterior part and vestibule. He concluded that the asepsis of the nasal cavities is due to the structure of the canal, to the ciliated epithelium, and to the germicidal quality of the mucus, which he found was absolute for anthrax, very marked for the Klebs-Loffler bacillus and less so for the staphylococcus and streptococcus organisms. Tyndall found that in the passage of the air through the nasal cavities its cleansing was accomplished by the action of the vibrissæ, the hairs of the vestibules which hinder the entrance of large particles, and by the adherence of smaller particles to the moist surfaces of the intricate passages of the nose and the nasopharynx. These surfaces are in turn cleansed by the action of the ciliated epithelium and the flow of mucus.

Regarding the tubercle bacillus, Allchin in his Manual of Medicine has the following to say:

"The tubercle bacillus is the direct cause of the various forms of laryngeal and pulmonary tuberculosis. There are three modes in which this bacillus may gain access to the respiratory tract, namely, inhalation, in- 
gestion and inoculation. By means of inhalation the bacillus is carried directly to the part which it affects. Numerous experiments have shown conclusively that the inhalation of air in which is suspended dried tuberculosis sputum will induce tuberculosis in even the most refractory animals. In the case of man it is by inhalation that the disease is most usually contracted, and we find that the lungs and bronchial glands are far more frequently affected with tubercle than any other parts of the body. A phthisical patient may, in the course of the day, expectorate millions of bacilli, and if he is careless in the disposal of his sputum must infect the place where he lives. It has been proved that dried sputum will retain its virulence for a long time. Experiments with dust collected in various quarters of Berlin by Cornet showed that nearly 33 percent of the specimens were infective, the dust being most frequently virulent in hospital wards and in private rooms occupied by consumptive patients. Recent experiments made by Coates, in Manchester, show that in houses which have been occupied by careless consumptive invalids the dust is infective in more than 50 percent of the cases. In no instance was the dust of even the dirtiest houses found to be infective, when no case of tuberculosis had occurred in them during the previous three years."

This being true, it is not difficult to conclude that mouth-breathing may, in many instances, be directly responsible for pulmonary tuberculosis. With the nasal passages closed, the mouth is opened for purposes of respiration, and the heavily loaded air containing tubercle bacilli, streptococci, staphylococci, pneumococci, the Klebs-Loffler bacillus and many more, is rushed directly into the larynx, trachea, bronchi and bronchioles.

So I repeat, that I would make first and most important in our treatment of these conditions, the idea of normal nasal respiration, that the air may be filtered, warmed and moistened before it enters the delicate tissues of the lungs.

Quoting from a recent article by Dr. E. A. Bogue, of New York, upon the relation of the dental arches to pathological affections of the nasopharynx, we have the following:

"Now that we know something about the proper size and relations of the dental arches, we know how mastication should be performed to get the greatest degree of vigor from the food we consume, and we know what steps should be taken to permit the child afflicted with adenoids to close its mouth.

"Dr. I. B. Davenport, of Paris, discovered in 1886 what normal dental arches were; also, that in civilized communities normal dental arches were rare. A few years afterward the late Dr. Bonwell, of Philadelphia, discovered that a mathematical relation existed between the width of the permanent upper central and lateral incisors and cuspid and the entire arch, and from the measurements of these three teeth he was able to construct the entire arch as it should be when normal.

"When thus normally arranged, it is found that all the teeth growing in one jaw articulate with the teeth of the other jaw to furnish the largest area of grinding surface. The cusps and the sides of the cusps, and the sulci into which they fit, all combine to furnish not only the best masticating surfaces, but to form dental arches that for strength and durability cannot in the human species be excelled. The cusps of all the grinding teeth in such 
arches, interlocking with their antagonists, prevent any variation in position of any of the teeth laterally or anteroposteriorly.

"Dr. Hawley, of Columbus, Ohio, recognizing these facts, adapted Dr. Bonwell's discovery to the use of the orthodontist. The result is that today by measuring the width of one upper central incisor we may determine approximately the shape and size of the arch in which that tooth belongs, and may draw it on paper so accurately that we may work to that arch with confidence. If there is any slight variation in the sizes of the various teeth in the same mouth and we work up to the model, nature will make all proper correction in the way of diminution and adjustment to type without assistance, and at the same time without any injury to size or strength or the adaptation of the arches to each other."

It is not my intention to enter into detail at all regarding the various methods of correcting nasal or dental deformities. Methods of correction applying to nasal irregularities are familiar to every practitioner. Correction of dental deformities must, of necessity, be left to the orthodontist. I am satisfied if this brief paper shall call to your minds a method of relief for your little patients, who still breathe through their mouths after all your careful ministrations.

I am indebted, in addition to credit already given, to Dr. Milton $T$. Watson, of Detroit, Mich., Dr. S. E. Dodson, of Grand Rapids, Mich., and Dr. Martin Dewey, of Kansas City, Mo., for many valuable suggestions from the standpoint of the orthodontist.

\section{DISCUSSION.}

M. A. Barndt (Milwaukee): This is a field in which $\mathrm{I}$ have been doing more or less thinking for some time. Like many others, have operated upon children for tonsils and adenoids and other nasal obstructions, and did not obtain the results that I expected; after meeting with a few of these cases I began to look farther into the subject and found that in many cases where the palatine arch was very high with malocclusion of the teeth, I had to be very cautious as to my prognosis. I specially remember one case of a little child that I had operated upon with comparatively no benefit; the dentist with whom I am associated began to regulate the teeth, to separate $t$ e palat ne arch, and when all was completed, we had a splendid result. Thus in my opinion all cases should be looked over carefully and all points taken into consideration. For simple removal of the adenoids, tonsils or perhaps a shrinking of the turbinals in cases where the palatine arch is high and there are other dental deformities, we must be guarded in our prognosis, otherwise we may be disappointed in our results. In cases of simple removal of the tonsils and adenoids or hypertrophied nasal tissue, where there is no malformation of the teeth, jaw or arches, we can obtain most excellent results, but if there are other obstructions we must certainly look farther, and the help from the orthodontist is certainly very gratifying.

The pressing of the tongue upon the palatine arch, the muscles of the cheek crowding the jaws together, the effort made by drawing air through obstructed nostrils, are all factors in maintaining these deformities. Other factors will aid somewhat in correcting these deformities, but are not sufficient to overcome the difficulties and form a perfectly shaped head and face. In my opinion the methods of correcting these deformities should be left entirely with men of experience along this line. I am satisfied that when we do all that we can in our line of work and do not meet with results, our patients are more than grateful if we can offer them something that will give them more relief by turning them over to the orthodontist.

Martin Dewey, M.D., D.D.S., (Kansas City): It has long been known that some relation existed between those who treat conditions and operate above the floor of the nose and those who do the same below the floor of the nose. Rhinologists have recognized the 
importance and need of someone that could obtain results in certain cases after they had done all they could. It is a fact, as Dr. Myers has stated, that the orthodontist was the first to call the attention of the medical world to the benefits which could be obtained by the proper treatment of this class of cases which have so long troubled rhinologists. You may not realize that in a large number of cases your final success is dependent on the work of the man who successfully treats teeth and dental arches. However, you can feel a sense of satisfaction by knowing that he too is dependent upon you in a large number of his cases. As I will show you, operations which are performed upon the teeth with a view of producing normal occlusion, the correction of dental deformities, play a large part in the proper development of the nasal cavities and thereby removing the existing nasal deformities in a large number of cases.

I will confine my remarks to mouth-breathers and to that class of patients who are, or have at some time been, sufferers from adenoids. This does not include all the cases in which the rhinologist and orthodontist work hand in hand, but for lack of time I cannot discuss all of them. And here I must warn you, there is a vast difference between the orthodontist and dentist; as much difference as there is between the rhinologist and general practitioner.

Experience has shown that there are different types of mouth-breathers, but I must again confine myself to that type which we find have been the result of adenoids, or, more correctly, lymphoid tissue. Experience has shown that this class of patients early in life have possessed normal dental arches and nasal cavities, also, that if the nasal obstruction was removed early enough the deformities would not take place. However, we as specialists hardly ever see these cases until enough harm has been done to call the parents' attention to the fact that the operative treatment is all that will give relief. If the nasal obstruction exists any length of time, mouth-breathing being persisted in during that time, we find deformities of the dental arch always result; these in turn have an evil influence on the nasal cavities.

After seeing the same class of cases so many times, we have come to the conclusion that adenoids are responsible for that class of malocclusion which is characterized by protruding upper anterior teeth, narrow upper arch, receding mandible and teeth, short npper lip and abnormal lip functions. In addition to cases in which adenoids are present there are also cases without adenoids; this only proves that the adenoids have disappeared for some cause and that the malocclusio is the mark which they always leave if they have been present any length of time. Therefore, an early removal of the adenoids is important; do not allow them to atrophy, as I find some recommending, for before they atrophy we will have a great deformity developed in the arches.

It is in the class of cases referred to that the rhinologist and orthodontist must work hand in hand. As Dr. Myers has said, you have operated on cases and removed everything in sight, yet the patient went on breathing through the mouth, not from habit but from necessity; necessity, because the dental arches are so deformed that the patient cannot close the lips without an effort which he will not make. Necessary, because the mouthbreathing has not only deformed the dental arches but has exerted an influence on the nasal cavities.

It is a fact that you cannot have any marked deformity of the dental arches without a deformity of the nasal cavities. As a result of this the "habit" cases breathe through the mouth because they cannot get the proper amount of air through the nasal openings. It is also known that you cannot remove this nasal deficiency by operating on the nose by any operation known to rhinology. The only help that I know of comes from the orthodontist after you have removed the nasal obstructions.

Some of you will no doubt ask, "How does this lack of development of the nasal cavities take place and how is it influenced by treatment of the dental arches?"

In the beginning I will say that while the orthodontist seems to be operating on the teeth directly, he is also operating on all of the bones of the face. The influence of his work cannot be estimated by what he does by way of improvement of the position of the teeth. When the lymphatic tissue has hypertrophied to such an extent as to obstruct the passage of air through the nose, we find the mouth-breathing takes place. As all of the muscles which depress the mandible also pull it backward, the mandible is held back to a certain extent; this continued abnormal muscular pull, day and night, soon has an evil effect on 
the development of the body of the mandibles. This accounts in part for the receding chin which we find in these cases.

Also the position of the tongue when the mouth is open influences the position of the lower teeth. Instead of occupying the entire oral cavity, we find it lying in the lower portion of the mouth and then not in its normal shape, but pulled down and back by the action of the hypoglossus; that is, the anterior end is pulled back so as to remove the pressure of the tongue from the anterior teeth. The position of the tongue in the normal breather has been spoken of by other men, and I will state briefly what it is and the influence it has on the growth of the arches and nasal cavities. In its normal position it fills the entire oral cavity. When the mouth is closed after speaking, we very soon swallow. In doing so a vacuum is formed and the tongue is forced against the roof of the mouth and against all of the teeth. The suction of the tongue against the roof of the mouth pulls the vault downward. There is also a lateral thrust of the tongue against the sides of the arches, which tends to stimulate their development in that direction. The continued action of the tongue as described in the course of weeks, months and years would amount to a great amount of force having been exerted. In mouth-breathing we find all of this is absent and the lack of it accounts to a great extent for the high vault and narrow upper arch which we have spoken of.

I wish to state that I do not think the vault or roof of the mouth, or arch of the palate (call it what you will) has been forced up, as some have said, but it has failed to be forced down. As the mouth is held open in the beginning of mouth-breathing, the teeth are apart. This invites a downward growth of the teeth and alveolar process which takes place. The vault does not grow down as rapidly as the process; therefore, in a short time it is high as compared to the teeth and process. In fact it is high as compared to the ethmoid bone; but do not get in the habit, as some have, of saying it has been forced upward. It is retarded in growth, caused by the lack of the suction of the tongue and the lack of nasal respiration. There may be other factors which exert an influence, but these are important and must be taken into consideration. With every normal act of respiration there is a force exerted in the nasal cavities which during the growing period of the child, is very necessary. It not only tends to expand the nasal cavity but also expands the sinuses as well. Therefore in mouth-breathers we would expect the underdevelopment which we always find.

The effect of the muscular action on the mandible has been spoken of. We also find that muscular action plays an important part in the shaping of the upper arch. During normal-breathing the orbicularis oris is active in closing the lips. When the lips are inactive, as they are in mouth-breathing, no pressure is exerted on the anterior teeth. The upper anterior teeth are permitted to protrude because of the removed pressure. They are further aided in the protrusion by the patient being forced to moisten the anterior part of the palate either with the tongue or lower lip. Each act just described pushes on the upper anterior teeth, as a result of which we soon have a glaring deformity. After the teeth and arches have become malformed the patient cannot close the lips without an effort, and mouth-breathing will persist regardless of what the rhinologist may do.

As a result of the chain of events which I have briefly called your attention to, we find the typical case of malocclusion and nasal deformities developed, the treatment of which we will now consider from the standpoint of both rhinologist and orthodontist.

The first step is the removal of adenoid tissue and other obstructions which were the beginning of the condition. Our next step is the changing of the position of the teeth and arches so as to establish normal occlusion, make it possible for the patient to close the lips, and stimulate the proper growth of the nasal cavities. You must remember that the maxilla and intermaxillary bones support the teeth of the upper arch. Also that they contribute to the formation of the walls and floor of the nasal cavity more than any other bones. You should now see the influence which their malformation exerts on the size of the nasal cavity. Take the typical case of narrow upper arch and high vault. By expanding the dental arch, we find the vault is pulled down. Take a visiting card and hold it between the thumb and finger in such a manner as to produce an arch. Release the end and you will see the arch come down. That is what takes place when the dental arch is expanded in the treatment of these cases.

The floor of the nose is pulled down to such an extent that deviation of the septum has been corrected. In fact we can expect such to be the result in 90 percent of deviated septums found in [young] mouth-breathers of the type spoken of. I should say 100 percent, 
for in all cases where the patient has been examined by the rhinologist before and after treatment the septum has been straightened. As the number so examined is not great we cannot be too sure of the continued success, but everything points to as good results in the future as we have had in the past.

With the pulling down of the floor of the nose, straightening of the septum, we also have an increase in the lateral dianeter of the nose. This greatly increases the nasal space, and after the arches have been so changed that the patient can close the lips and teeth everything is favorable for nasal respiration.

You now see how, by enlisting the aid of the orthodontist, you will be able to do things for your patient that you have heretofore considered impossible. In doing the most good for your patients you must recognize the necessity of the orthodontist as he has recognized his inability without your aid. If I have succeeded in impressing upon you the relation bet ween rhinology and orthodontia, I feel greatly repaid.

H. S. Weaver (Philadelphia): There is just one thing that I wish to call attention to, and that is the age of the patient; you will find that adenoids are not limited in their occurrence to children. Within the last year I operated upon a man for adenoids where the postnasal space was entirely filled with them. He never remembered being able to breathe through his nose, and hence had probably had them all his life. He was an unusually heavy set man, weighing about two hundred pounds. Owing to the age of the patient I thought the trouble could not be due to adenoids. I tried to get a view of the postnasal space with the rhinoscope but could not. I then introduced my finger and found as typical a case as I ever found in any child. At the operation I found the adenoids tough; the curette was useless, I could not do anything with it. I finally had to go in with adenoid forceps and literally tear them out piecemeal.

The dental arch was contracted, the teeth protruded and the nose was not well developed. His age was forty-nine. I do not remember ever seeing a case of that age reported. I had to do some work on the turbinated bodies. I obtained fair nasal respiration; he breathes through the nose as long as he is awake but at night still uses his mouth.

\section{E. W. Beebe: Were the growths fibrous in character?}

Dr. Weaver: They were fibrous and as tough as leather.

Isaae C. Soule (Kansas Cisy): I had last year an interesting case that illustrates the influence of abnormal formation of the dental arches. The patient was seventeen years old with poor development of the nasal organs owing to partial occlusion of the postnasal space by adenoíds. These were removed without any appreciable effect on the mouthbreathing. I urged the parents to go to a dentist and have the teeth attended to, but could not influence them. Shortly after the girl was in an accident, being thrown out of a buggy while the horse was running away. The upper teeth were knocked out and the alveolar processes crushed. Then she had to be taken to a dentist, and as a result of the accident and the work done some of the narrowness of the dental arch was relieved and she has breathed better ever since.

C. Gurnee Fellows (Chicago): Somebody suggested that it was impossible to send a patient to an orthodontist in most parts of the country because there were not many of them; it was not possible to send a patient to an eye or ear specialist twenty years ago, except in the largest cities.

If we find that the orthodontists are a help to us, and we begin to make use of their services, it will not be long before there will be plenty of them, and we can avail ourselves of their help even in the smaller towns. I have sent cases to dentists many times, but now that I have learned something I never knew before I shall send them to the orthodontist for an opinion in regard to teeth and mouth deformities.

Burton Haseltine (Chicago): It is no doubt a fact that we have not fully enough recognized the bearing of mouth trouble upon certain cases of mouth-breathing, but it would be a serious mistake to suppose that any large number of septum deformities can or could be cured in this way. As a rule the septum deformity is a late thing. It does not usually come to us until some time after the mouth-breathing habit has been established. The widening of the dental arch might correct a slight curve perhaps, but the usual septum 
deflection is a much more complicated thing than simply a bending pure and simple of the septum to one side; it is thickened and hypertrophied, much more like those callosities that occur around the ends of broken bones that are not properly approximated. Such a condition cannot be cured by any pulling down of the palatal roof or straightening of the dental arch. No doubt the orthodontist could prevent the deformity by his work in the mouth if he saw the case early in life, but by the time we generally see them, deflections of the septum require operative work in the nose and often extensive work, too.

Dr. Weaver: I should like to know what the doctor's experience has been in regard to the recurrence of jaw malformation after operation for its correction. I have seen cases where the deformity was returned within a year after the operation almost as bad as it was before.

Dr. Dewey: The removal of a malformation without the removal of its cause is not a cure, Remove the adenoids by all means, but they will come back in all probability unless you also remove that prior condition upon which they are based.

Dr. Myers: I am very glad this paper has brought out the discussion it has, and hope it may serve to call attention to an important but neglected subject. From what Dr. Haseltine has said I think he misunderstood Dr. Dewey. Dr. Dewey means that the case must be taken in its early stages in order to correct septal deflections. He did not mean that orthodontia would correct deformities depending upon thick calluses. We often find in cases of apparently deflected septum that there is no depression of what should be the concave side, but instead simply a thickening of the septum in the occluded side. Of course no one would expect to correct a deformity of that kind simply by work in the mouth. But this work is invaluable in its place. Dr. Weaver's case was an interesting one; the adenoids had been there since a very early age and had never cured themselves nor been removed. Adenoids do not always disappear with advancing years. If in that case there had been an operation early for their removal and nothing else done they would have recurred. With dental deformities uncorrected, our adenoid operations are very often failures, and we have noticed again and again the recurrence of adenoid tissue and the regrowth of the tonsils. Another point that we should notice is the needless and promiscuous extraction of teeth, much irreparable deformity resulting therefrom. A whole lot might be said upon that subject, and we should put forth every effort to stop the practice. 